\title{
Mulheres ciganas: medo, relações intergrupais e confrontos identitários
}

\section{Gypsy Women: Fear, intergroup relations and identity conflicts}

\author{
MARIANA BONOMO* \\ LÍDIO DE SOUZA \\ Zeidi Araujo TRINDADE \\ Fabiana Davel CANAL \\ Julia Alves Brasil \\ ANDRÉ MOTA DO LIVRAMENTO \\ ana Paula da Silva Milani Patrocínio \\ Centro de Ciências Humanas e Naturais, \\ Universidade Federal do Espírito Santo, Brasil
}

RES U M O

Através da Teoria da Identidade Social procurou-se conhecer os estereótipos presentes no imaginário rural associados ao grupo cigano, bem como os sentimentos associados a esta etnia. Foram entrevistadas 10 mulheres não-ciganas, moradoras de uma comunidade rural brasileira. Realizou-se a organização dos dados através do software ALCESTE. A análise das informações nos permitiu identificar o sentimento de medo como importante orientador das práticas relacionadas aos ciganos, confirmando características presentes no imaginário social amplamente difundido acerca desta etnia. Estão presentes os clássicos estereótipos de ladrões, malfeitores e amaldiçoados. Discute-se a dinâmica identitária provocada pelo conflito entre a comunidade rural e os ciganos, enfatizando os processos que orientam o campo de identificação e diferenciação endo/exogrupal.

Palavras-chave autores

Exclusão, identidade social, medo, mulher cigana, mulher rural.

Palavras-chave plus

Cultura, estudios culturales, movimientos sociales, psicología social.

\section{A B S T R A C T}

Through the Theory of Social Identity our objective was to know the stereotypes present in the rural imaginary related to the gypsy group, and the feelings associated with this ethnic group. Ten women, non-gypsies, residents of a rural Brazilian community, participated in this study. We analyzed the data through the ALCESTE software. The analysis of the information obtained has allowed us to identify the feeling of fear as the main mediator of practices related to the gypsies, confirming characteristics widely present in the social imaginary about this ethnic group. There are present the classic stereotypes of thieves, criminals and the cursed. It discusses the dynamics of identity provoked by the conflict between the rural community and the gypsies, emphasizing the processes that guide the field of identification and differentiation in/out-group.

Key words authors

Exclusion, social identity, fear, gypsy woman, rural woman.

Key words plus

Culture, cultural studies, social movements, social psychology. 


\section{Introdução}

Desde o nascimento os indivíduos se relacionam com o mundo a partir de um conjunto organizado de conhecimentos e sentimentos que lhes permitem o desenvolvimento do sentido de pertencimento e, consequentemente, de categorização do outro. À medida que o desenvolvimento se processa, os nossos sentimentos vão sendo fortemente marcados por regras e normas sociais, definidas pelos grupos sociais aos quais reconhecemos pertencer. A dimensão afetiva assume, então, funções comunicativas e de sociabilidade, podendo favorecer o afastamento ou a aproximação entre os grupos e as pessoas (Leite, 1999).

Carvalho, Machado e Suyama (2002) argumentam que o desenvolvimento do ser humano ocorre "através do confronto de ações, emoções, motivações e significados" (p. 47), sendo este um importante processo de construção do indivíduo, bem como das práticas sociais por ele vivenciadas, posto que a própria rede de interações é parte da rede social simbólica, constituída em um contexto histórico determinado, caracterizado por elementos culturais, econômicos, políticos e ideológicos. Neste contexto se organizam os valores atribuídos aos diferentes grupos sociais, bem como o medo de determinados grupos humanos. Glassner (2003) informa que o medo na atualidade envolve um processo de manipulação cuja trama esconde o interesse econômico na obtenção de lucro com determinadas formas de medos e insegurança, que são alimentadas nos mais diversos veículos de comunicação de massa. Vivemos, assim, entre a difusão de uma cultura do medo, um sentimento individual e socialmente partilhado, referenciado por objetos sociais que são oferecidos às nossas relações cotidianas já interpretados e revestidos de uma ideologia que contribui para a discriminação (Fiorin, 2004).

Martins (2004) fornece elementos importantes para a compreensão de como esse processo se organiza na vida cotidiana dos indivíduos. $\mathrm{O}$ autor explica que o sentimento de medo está ligado à nossa relação com eventos futuros, preparando-nos para fugir de um perigo que pode ser real ou imaginário: "uma espécie de aviso da possibilidade de alguma ameaça ao organismo" (p. 55). À medida que nos desenvolvemos vamos aprendendo a identificar e fugir dessas situações potencialmente perigosas, sendo esse aprendizado diferente de sociedade para sociedade, cultura para cultura e, até mesmo, de indivíduo para indivíduo. Como destaca Leite (1999), os sentimentos atendem a uma necessidade do organismo, refletindo "as exigências, as normas e valores historicamente acumulados e assimilados pelo homem individualmente" (p. 96). Há, portanto, um compartilhamento individual dessa estrutura simbólica com a qual dialogamos cotidianamente, em um processo de assimilação ativa, rejeitando e incorporando os conteúdos imagéticos que nos permitirão nos reconhecer como indivíduos - frutos de um conjunto de relações sociais, orientadas pelos diferentes grupos de que fazemos parte, nos quais tecemos, incessantemente, a nossa identidade social.

É neste sentido que Walton (2007) destaca que até mesmo um simples desconforto em relação aos hábitos do vizinho do lado pode passar de um ato inocente para uma ideologia de amargura e conflito. Não podemos nos esquecer, contudo, que a própria história da humanidade é uma história de conflitos, contada pelos rastros do confronto entre grupos diversos em diferentes épocas, confronto que visa criar e manter espaços in-group (Funari, 2006). Embora tais conflitos possam ter motivações político-econômicas, são, sobretudo, processos simbólicos que ocorrem no contexto políticoideológico. Em síntese, nos constituímos em um processo no qual o medo, ao estabelecer fronteiras entre os grupos sociais, alimenta determinados estereótipos e orienta práticas intergrupais. Delumeau (2007) esclarece:

A raiz disso se encontra na apreensão provocada entre pessoas que não se conhecem, ou que se conhecem mal, que vêm de fora, que não se parecem conosco e que, sobretudo, não vivem da mesma maneira que vivemos. Falam uma outra língua e têm códigos que não compreendemos. Têm costumes, comportamentos, práticas culturais que diferem das nossas, não se vestem como nós, não comem como 
nós, têm religião, cerimônias e ritos cujo significado nos escapa. Por todas essas razões, eles nos assustam e somos tentados a tomá-los como bodes expiatórios em caso de perigo. Se uma desgraça acontece a uma coletividade, é por causa do estrangeiro. (p. 46)

A importante questão que decorre deste processo é o uso ideológico que dele se faz, uma vez que a profusão de estereótipos e práticas associadas a determinados grupos sociais concorrem para a construção de grupos depositários reforçando a manutenção de representações marginais e concretizando a identidade como ideologia separatista (Sawaia, 2001). É a partir desta lógica que aprendemos a sentir medo de determinados grupos de pessoas, lugares, ideologias e, por conseguinte, a agir e a avaliar negativamente esse "outro", marcando nosso próprio espaço identitário. Esta parece ser a condição de um grupo milenar, que fez da exclusão itinerante uma cultura de liberdade: os ciganos.

\section{Exclusão social e medo: trajetória do grupo cigano no mundo ocidental}

O imaginário social organiza-se como "memória afetivo-social de uma cultura, um substrato ideológico mantido pela comunidade" (Moraes, 2002, s.p.), sendo coletivamente produzido e depositário privilegiado da memória que os diferentes grupos sociais recolhem de suas relações cotidianas. Este imaginário orienta as práticas sociais futuras e mantém certa ordem e equilíbrio na tessitura social.

Entre as representações que compõem o imaginário social ocidental acerca do grupo étnico cigano, encontramos o medo como um dos elementos centrais que regulam práticas de exclusão e a elaboração de estereótipos negativos amplamente sustentados e difundidos entre os grupos não ciganos (Magano, 2007). Sobre a transmissão e reforçamento de determinados estereótipos, em um estudo feito por Fandos e Martínez (1999), os pesquisadores realizaram um levantamento sobre imagens estereotipadas presentes em determinadas produções da mídia. Entre os personagens da vida real reproduzidos nas categorias focalizadas (profissionais, familiares, sociais, culturais e nacionais) temos, por exemplo: a sogra, sempre representada como uma figura dominante e resmungona; a responsável pela portaria, ilustrada como uma mulher curiosa e intrometida; ou mesmos os ricos que são retratados a partir da imagem dos chamados "emergentes" ou dos novos ricos, que se comportam de maneira exibicionista e são representados como pessoas ignorantes. Entre as imagens estudadas, também estão presentes os clássicos estereótipos associados aos ciganos: "ladrones y nada amantes del trabajo" (Fandos \& Martinez, 1999, p. 119).

Integrantes de uma cultura marcada por séculos de injustiças, preconceitos e perseguições, os ciganos sofrem, até os dias atuais, o reflexo de uma história de sofrimento e marginalização (Coutinho, 2002). Fatos recentes na Europa registram a perseguição à população cigana. Em países como Itália, Romênia e França, acampamentos ciganos foram incendiados recentemente e os seus habitantes expulsos (Giornale La Repubblica, Itália). Ao contrário do que propõem as políticas em favor das comunidades ciganas, nomeadas pela União Européia como "La Década para la Inclusión de los Gitanos” (Fundación Secretariado Gitano, 2005), o que presenciamos são fatos que continuam marcando negativamente a história deste grupo. $\mathrm{O}$ desrespeito à cultura desse povo é identificado não só nos fatos acima citados, mas também nas tentativas de aculturação. A inserção dessa população é promovida não pelo respeito a suas especificidades culturais, mas pela imposição de modos de vida que não são próprios da sua cultura, com o intuito de minimizar conflitos e incômodos aos citadinos não ciganos.

No Brasil, também se verifica o descaso com a cultura cigana. Apesar de a Constituição Federal brasileira garantir os mesmos direitos a todos que nascem no país, na prática eles são violados quando se trata de populações pertencentes a minorias étnicas, e com os ciganos, não é diferente (Vaz, 2005). Representantes da Associação de Preservação da Cultura Cigana (APRECI) estimam que mais de meio milhão de ciganos vivam em território brasileiro, muitos deles não registrados. As dificuldades de acesso à educação e ao sistema público de saúde, por exemplo, demonstram o quanto ainda é 
preciso avançar nas políticas públicas pró-ciganas para que eles possam gozar dos direitos básicos preconizados para todo ser humano.

Algumas conquistas foram garantidas a partir de maio de 2008, quando os ciganos passaram a ter o direito de ser atendidos em unidades de saúde e hospitais da rede pública, mesmo sem a apresentação de documento de identidade ou comprovante de endereço. Ainda em 2008, a Secretaria Especial de Direitos Humanos da Presidência da República também criou a cartilha "Povo Cigano - o direito em suas mãos", documento que defende a inviolabilidade dos acampamentos ciganos e o direito ao uso de trajes típicos pelas mulheres em qualquer estabelecimento, entre outros (Agência Brasil). No entanto, é preciso ter cautela, pois tais iniciativas podem servir de artifício para encobrir a verdadeira situação dos ciganos brasileiros. O desconhecimento sobre a cultura cigana parece ainda estar intimamente relacionado a uma "identidade estigmatizada" (Wacquant, 2004) difundida no imaginário social, onde são recorrentemente representados como: sujos, ladrões e portadores do mal (Alexandre, 2003; Fonseca, 1996). Dessa forma, preconceito, medo e discriminação, mantêm este povo como estrangeiro, apesar de sua presença secular no país.

\section{Identidade social e processos grupais}

Considerando o interesse em focalizar os processos grupais em torno da ciganidade como objeto social, entende-se que a Teoria da Identidade Social (TIS), tal como proposta por Henri Tajfel, apresenta-se como um valioso recurso teórico. A teoria procura elucidar a constituição da identidade no âmbito das relações intergrupais, enfatizando os processos que delimitam um determinado campo de identificação. Os conceitos fundamentais que contribuem para elucidar os processos identitários estão em um arranjo interdependente na dinâmica C.I.C.: Categorização social -Identidade socialComparação social (Hogg \& Abrams, 1988; Hogg, Abrams, Otten \& Hinkle, 2004; Tajfel, 1970, 1972, 1974, 1982a, 1982b, 1982c, 1983, 1984).
Para Tajfel (1983), a categorização social é o processo no qual "se reúnem os objectos ou acontecimentos sociais em grupos, que são equivalentes no que diz respeito às ações, intenções e sistemas de crenças do indivíduo" (p. 290). Este processo decorre da necessidade e da capacidade cognitiva de apreender os elementos disponíveis nos diversos contextos sociais, agindo como um princípio ordenador da realidade que define as fronteiras entre o "dentro" ou endogrupo e o "fora" ou exogrupo. A categorização social é considerada o coração cognitivo dos processos de identificação (Hogg et al., 2004), visto que abarca os processos sóciopsicológicos que ordenam o mundo em termos de categorias: grupos de pessoas, de objetos, de acontecimentos (Tajfel, 1972). O processo permite ainda a elaboração de estereótipos que protegem os indivíduos que pertencem a um determinado grupo, munindo-os de recursos simbólicos.

Este processo só é possível através da comparação social, que compreende o confronto entre o "próprio grupo" e os "grupos de relação", compondo o mecanismo central para a construção da identidade social. Assim, o conceito que o indivíduo tem de si, a construção de sua identidade, "deriva do seu conhecimento da sua pertença a um grupo (ou grupos) social, juntamente com o significado emocional e de valor associado àquela pertença" (Tajfel, 1983, p. 290). Nas relações estabelecidas entre os grupos sociais, como discutidas por Souza (2004), operam os processos de categorização e comparação social que portam "as possibilidades de produção de solidariedade e exclusão a partir das identificações sociais" (pp. 66-67). Solidariedade e exclusão parecem se encontrar na dependência do quanto o indivíduo se sente seguro ou inseguro, protegido ou ameaçado nas relações intergrupais.

A questão da insegurança, conforme Amerio (2004), é um dos fios condutores da sociabilidade contemporânea. $\mathrm{O}$ autor argumenta que a insegurança pode ser compreendida como um estado psicológico resultante de percepções e avaliações, emoções, preocupações e inquietudes emergentes no curso da relação entre o indivíduo e o contexto material e simbólico. Faz-se necessário, portanto, pensar os processos psicológicos e as situações 
sociais que produzem o estado de insegurança cristalizado no sentimento do medo.

Moser (2004) considera que o sentimento de medo aparece como uma reação afetiva do indivíduo à hostilidade do ambiente. Frente a esse sentimento, estratégias são usadas pelo grupo ameaçado, que procura manter o estado de segurança endogrupal minimizando os conflitos internos e associando o perigo presente ao ambiente externo, produzindo um sistema paradoxal e interdependente entre o sentimento de segurança e o de vulnerabilidade. Nesta perspectiva, a estratégia adotada pelos indivíduos, a fim de que esse estado seja assegurado, é a de estabelecer linhas sociais e sentimento de pertença a uma comunidade (Moser, 2004).

Considerando a longa história de exclusão vivenciada pelos grupos ciganos objetivamos com esta investigação (1) conhecer alguns dos elementos que compõem os estereótipos presentes no imaginário rural acerca do grupo étnico cigano, bem como os sentimentos associados ao grupo. Tendo em vista que as relações entre grupos ciganos e não ciganos poderiam favorecer a apreensão mais nítida dos processos identitários, a investigação objetivou também (2) verificar como o medo medeia a elaboração de identidades e práticas sociais de solidariedade e exclusão.

\section{Estratégias metodológicas}

\section{O campo de investigação}

Trata-se de um estudo exploratório cujo campo de investigação empírica se constituiu em uma comunidade rural, território que se configurava como rota esporádica de passagens de grupos ciganos nômades. Essa relação entre a comunidade e os ciganos favoreceu o acesso ao conteúdo analisado no presente estudo. Faz-se necessário ressaltar ainda que as relações entre as comunidades rural não-cigana e cigana se estabeleciam principalmente através das mulheres. Eram as mulheres ciganas, que na época das viagens, saíam pelas casas da região onde estavam acampadas com o objetivo de conseguir comida e encontravam as mulheres rurais, já que estas são as responsáveis pelo cuidado com os filhos e com a casa, enquanto aos homens do grupo rural compete prioritariamente o trabalho nas lavouras. É através de um grupo de mulheres da comunidade rural, portanto, que procuramos conhecer os elementos que organizam as práticas de exclusão e o medo sentido pelas mulheres rurais em relação aos nômades ciganos simbolizados principalmente nas práticas das mulheres ciganas.

\section{Participantes}

Foram entrevistadas 10 mulheres rurais não ciganas, com idades entre 34 e 67 anos; 09 casadas e 01 divorciada; 04 não eram escolarizadas, 04 tinham o ensino primário e 02 o ensino fundamental; todas moradoras de uma mesma comunidade rural localizada no interior de um estado brasileiro. As participantes exerciam atividades ligadas à agricultura e se reconheciam como mulheres rurais e mães de família, o que lhes conferia a responsabilidade do cuidado com os filhos, marido e pequenas criações de animais e cultivo de hortaliças.

É importante registrar que todas as participantes enfatizaram a dificuldade em falar do grupo cigano, pois a comunidade procurava rapidamente esquecê-los assim que estes abandonavam o espaço rural. Os ciganos eram objeto de discussão entre os moradores apenas durante o tempo em que estavam acampados em seu território. A comunidade usava a estratégia do esquecimento como forma de bani-los da memória social do endogrupo, visto que os ciganos não eram bem-vindos e, tampouco, eram considerados parte da comunidade.

\section{Instrumento e procedimento de coleta dos dados}

Os dados foram coletados através de entrevistas orientadas por um roteiro semiestruturado organizado em três módulos de informação: a) dados pessoais das participantes; $b$ ) questões sobre o cotidiano da comunidade rural (atividades e funcionamento geral da vida da comunidade investigada) e c) questões contemplando o grupo cigano, tanto na dimensão representacional (estereótipos e sen- 
timentos associados ao grupo), quanto nas práticas do grupo rural em relação aos ciganos (relatos de contato entre os grupos, possíveis mudanças na rotina da comunidade rural, se as mulheres rurais recebiam as ciganas em suas casas ou ainda se visitavam os ciganos em suas tendas).

Após informações gerais sobre os objetivos e procedimentos que seriam utilizados na pesquisa, bem como da leitura e assinatura do Termo de Consentimento Livre e Esclarecido, as entrevistas foram realizadas nas próprias residências das participantes com a utilização de gravador. Avaliamos que o tema investigado, bem como os procedimentos utilizados, não apresentaram qualquer tipo de risco, desconforto ou dano para as participantes.

\section{Procedimento de organização dos dados}

O tratamento dos dados foi realizado através do software ALCESTE (Reinert, 1990), que organiza o banco de dados a partir de unidades básicas de análise - Unidade de Contexto Inicial (UCI), sendo que cada entrevista corresponde a uma UCI e Unidade de Contexto Elementar (UCE), que são fragmentos do corpus selecionados pelo software. $\mathrm{O}$ ALCESTE realiza uma Classificação Hierárquica Descendente (CHD) sugerindo a formação de campos semânticos em função da semelhança do léxico e o resultado desta análise é apresentado na forma de um Dendrograma (Camargo, 2005).

O Dendrograma permite a visualização da disposição das classes em conjunto, nas quais são apresentadas as palavras mais representativas, segundo o valor do qui-quadrado (Kronberger \& Wagner, 2002). Possibilita visualizar também a força de ligação entre as classes, a porcentagem de cada classe no corpus analisado e a quantidade de UCEs pertencente a cada categoria (Bonomo, Trindade, Souza \& Coutinho, 2008). A utilização do ALCESTE permite classificar, assimilar e sintetizar um texto, capturando as redes de significado que organizam um sentido comum àquele conjunto de dados (Camargo, 2005; Lima, 2008).

\section{Resultados}

\section{Medo: a identidade social e o conflito místico}

A partir da análise das $10 \mathrm{UCIs}$, realizada pelo software ALCESTE, houve o aproveitamento de $76.07 \%$ de todo o corpus processado, fornecendo um conjunto de 192 UCEs. O programa organizou os dados em quatro classes, divididas em dois eixos principais: 1) Imaginário do medo, reforçado por experiências negativas, formado pela primeira e terceira classes, e 2) Conflito místico e identidade social, constituído pela segunda e quarta classes. Na Figura 1, podemos observar a análise realizada pelo software e a organização das palavras estatisticamente mais significativas em cada classe (foram selecionadas as 10 palavras com maior qui-quadrado).

$\mathrm{Na}$ Classe 1, O medo dos ciganos, os elementos destacados indicam a tensão vivida na relação entre a comunidade rural e o grupo cigano, conteúdo fortemente associado ao contato estabelecido com este grupo (Classe 3), como podemos conferir nas narrativas a seguir:

Eu fui criada naquele medo. Papai dizia: cuidado com cigano! Cuidado com cigano! Aquele medo foi crescendo na gente"; "A maior coisa que falava quando vinha... 'está vindo cigano!' Então, o que a gente fazia? Trancava a casa! 'Vamos fechar a casa, tirar as roupas do varal, porque está vindo cigano e eles rouba tudo'.

O medo que a comunidade sente dos ciganos está alicerçado nos estereótipos clássicos arraigados no imaginário social e dificultam a interação com outros grupos. As UCEs destacadas são ilustrativas dessa relação entre o medo e as práticas de exclusão:

"Mas o pessoal ficava com medo, fechava as portas, ficava com medo que eles vinham entrar. Falava que era a turma de bandalheiro, gente que não tem onde ficar, que ficava andando, fica agredindo. Eles não respeitam a gente"; "O pessoal fica com medo, fecha as portas, não quer dar lugar pra eles ficar". 
Figura 1

Dendrograma - Análise Hierárquica Descendente $n=10$

\begin{tabular}{|c|c|c|c|c|c|c|c|}
\hline & & & & & $\mathrm{R}=$ & & \\
\hline \multicolumn{2}{|c|}{$\begin{array}{c}\text { Cl. } 1 \\
\text { O medo dos ciganos }\end{array}$} & \multicolumn{2}{|c|}{$\begin{array}{c}\text { Cl. } 3 \\
\text { Contato com o grupo cigano }\end{array}$} & \multicolumn{2}{|c|}{$\begin{array}{c}\text { Cl. } 2 \\
\text { Prática mística }\end{array}$} & \multicolumn{2}{|c|}{$\begin{array}{c}\text { Cl. } 4 \\
\text { Nós e elas, as ciganas }\end{array}$} \\
\hline Termo & $x^{2}$ & Termo & $x^{2}$ & Termo & $x^{2}$ & Termo & $x^{2}$ \\
\hline Dentro & 24.42 & Briga & 81.21 & Querem & 30.77 & Acho & 30.76 \\
\hline Casas & 18.73 & Ficou & 48.55 & Ler sorte & 20.83 & São & 26.36 \\
\hline Minha & 12.30 & Veio & 27.79 & Pessoas & 18.45 & Mulher cigana & 21.15 \\
\hline Barraca & 11.50 & Tiro & 26.64 & Saber & 16.39 & Simples & 20.09 \\
\hline Café & 10.93 & Lembro & 21.00 & Benzer & 13.74 & Somos & 18.26 \\
\hline Medo & 09.28 & Cigano & 19.25 & Dinheiro & 13.74 & Mulher rural & 15.44 \\
\hline Portas & 09.25 & Comunidade & 19.08 & Gosta & 10.25 & Direito & 14.19 \\
\hline Antigamente & 07.67 & Passava & 18.26 & Não gosto & 10.25 & Delas & 10.46 \\
\hline Cuidado & 07.67 & Aqui & 13.35 & Luta & 10.25 & Grupo & 10.04 \\
\hline Roubar & 06.10 & Acredito & 10.33 & Passam & 06.71 & Vida & 08.43 \\
\hline \multicolumn{2}{|c|}{$77 \mathrm{UCE}-40.1 \%$} & \multicolumn{2}{|c|}{$20 \mathrm{UCE}-22.9 \%$} & \multicolumn{2}{|c|}{$44 \mathrm{UCE}-10.4 \%$} & \multicolumn{2}{|c|}{$51 \mathrm{UCE}-26.5 \%$} \\
\hline \multicolumn{4}{|c|}{ Imaginário do medo } & \multicolumn{4}{|c|}{ Conflito místico e identidade étnica } \\
\hline
\end{tabular}

Assim, as diferenças entre os dois grupos são fortemente reforçadas, buscando sempre afirmar a imagem dos ciganos como pessoas portadoras de características negativas (como roubar, jogar pragas e não trabalhar). A considerável simplificação presente no processo de simbolização faz com que o grupo rural procure, mais do que uma nova interpretação, uma constatação das características negativas que definem o grupo cigano, como podemos observar nas UCEs abaixo:

"Mas se a pessoa começa a agredir, começa a fazer coisa que não está no alcance, ou sente medo, ou sente até bravura. Você tem que começar a agir porque eles ameaça entrar dentro de casa, ameaça com xingamento forte. Se você tem medo, você tem que fechar as portas e não dar atenção"; "Eu sei que ela me joga praga. Eu respondi que praga de urubu velho não pegava em cavalo gordo. Ela foi embora brava. Eu não senti nada, eu não acredito nisso. Eu só tinha aquele medo de cigano que eu me arrepiava todinha quando ela conversava com a gente".

A Classe 3 refere-se ao contato estabelecido entre a comunidade rural e grupos ciganos. Os elementos presentes nesta classe referem-se a um conflito interno ocorrido por ocasião da celebração de um casamento cigano, planejado para aconte- 
cer nos domínios da comunidade, que serviu para fortalecer ainda mais a já consolidada identidade cigana e para justificar o afastamento em relação a esse grupo.

"Essa ficou marcante. Nossa Senhora! Os ciganos se atiraram por ali, uns veio se esconder por aqui, uns se afundaram nas matas. Foi uma briga, uma briga! Uma turma tava embarracada ali e chegou os cariocas"; "Aqui na comunidade que eu lembro dos ciganos, que ficou marcado, foi uma vez que eles vieram. Primeiro veio um grupo de cigano, depois veio outro. Marcaram um casamento pra fazer na comunidade".

Ainda tendo como pano de fundo o casamento que deveria ocorrer na comunidade, os elementos sugerem a violência como um dos traços do grupo:

"Graças a Deus que não matou ninguém. Foi uma briga feia mesmo. Isso a gente quase nem conversa, mas todos sabem porque, tempos passados, eles vieram receber dívida de não sei quem, então a gente sabe que o trem é barra pesada"; "A maneira que foi passada, o que é cigano pra nós, o que nós entendemos de ciganos, então, tinha essa discriminação que cigano era gente brava, gente ruim, passava essas imagens... cigano é ladrão, cigano mata, cigano rouba. Era tudo isso que passava de cigano, era uma tradição pra outra”.

Quando ocorre um contato mais próximo, como as visitas das mulheres rurais às barracas, o intuito principal é conhecer um ambiente que é estranho, que não é compartilhado. Contudo, como podemos ver na UCE a seguir, esse contato nem sempre é possível:

"Tem um time de mulher aqui da comunidade que ia na barraca, mas eu não. Eu sempre me afastei. Elas são imundas".

A Classe 2 apresenta a prática mística das ciganas, na qual se encontra a leitura de mãos e a benzedura entre outros elementos.
"Elas chegam na casa da gente, já chega pedindo. Pede pra você dar uma coisa, pede outra, pede outra, quer ler a sorte, fala que quer ler a sorte da gente, e se a gente não quiser, elas insistem".

De modo geral, as mulheres rurais depreciam essas práticas, demonstrando sentimentos como raiva e indignação, conforme podemos verificar nas UCEs indicadas a seguir.

"[...] de inflamação, problema de traição de marido, essas coisas... então, elas já pensam nessas coisas que todo mundo passa, então, elas chega falando que você tem esse problema pra elas poderem te benzer pra elas poderem ganhar dinheiro"; "Mas elas podem querer fazer coisas assim, que a gente não gosta. A gente tem uma cultura, eles têm outra. Uma vez que a pessoa fere a cultura da gente, você fica ofendida. Não seria fazer o mal, o mal, mas seria uma coisa desagradável, que a gente não aceita"; "Eu acho que é por isso. Querer obrigar a gente a dar uma coisa que a gente não quer. E elas têm muito esse negócio de benzer. Elas querem muito benzer a gente, benzer. E eu não sou muito chegada a esse negócio de benzer. E elas são uma tentação. Elas te perturbam que quer te benzer".

Assim, verifica-se o confronto entre os grupos - o que as ciganas gostam e querem, as mulheres rurais não gostam e desaprovam -, dinâmica que também está vinculada ao sentimento de medo e ao suposto poder místico inerente à prática da quiromancia.

"Tem medo! Porque elas faz pressão psicológica em cima da pessoa. Elas chega falando, achando que sabe, que sabe da vida das pessoas. Chega com mentira, falando que os maridos das mulheres têm outras mulher, vem falando esses trem que nem sabe de nada".

Verifica-se que essa prática conflituosa organiza o campo de identificação social entre os dois grupos e contribui para converter o aparente incômodo em medo das imprecações. 
"É passado que cigano explora, tem o poder de mente, que eles adivinha, vê a mão das pessoas e adivinha o que a pessoa faz, o que ela é"; "Tem cigana que vem e faz medo mesmo. Elas podem fazer mal a gente. Elas pedem uma coisa, se a gente nega, elas joga praga, fala que faz isso, faz aquilo, a gente sente assim, um medo".

Neste processo de comparação social, tão importante quanto valorizar o próprio grupo é a reposição dos estereótipos negativos relacionados aos outros grupos. Assim, em defesa da identidade social do próprio grupo, buscam distinguir quem faz parte da comunidade e quem é o "outro", demarcando o lugar do estrangeiro. É neste sentido que a prática mística está fortemente ligada à Classe 4, "Nós e elas, as ciganas" (Figura 1).

Os elementos contidos na Classe 4 indicam a distinção entre o grupo de pertencimento e o "outro grupo", composto pelas ciganas, que não é reconhecido como parte da comunidade rural. Quanto ao próprio grupo, as participantes destacam o universo feminino característico do mundo campesino, que prescreve a inserção das mulheres no trabalho agrícola, nas atividades domésticas e na esfera comunitária.

"Nós somos tudo! Eu acho que primeira coisa, tem capacidade, trabalham, somos todas mulher rural, trabalhadoras, tanto cuidam da casa quanto da roça, das coisas da comunidade, se dedica o tempo a ajudar uma a outra, são mulheres dedicadas no seu trabalho".

Em relação às mulheres ciganas, novamente foram identificados os clássicos estereótipos que regulam a interpretação sobre o modo de vida cigano e o desqualificam.

"Eu sei que talvez é um costume delas, mas eu entendo assim, umas mulher sofrida, sem direito, sem direito de vida, de ter seu trabalho pra fazer. Eu vejo isso nela. Eu acho que a vida de mulher cigana não é uma vida boa não"; "Deus me livre! Sei lá, eu penso assim, que as mulher cigana, vive aí... grupos de ciganos, vive jogado pra lá, não tem uma coisa assim, organizada. A vida delas é jogada. Vive lá de qualquer maneira, não tem uma coisa. Eu penso que o dia-a-dia não deve ser bom”.

\section{Discussão}

\section{Dinâmica C.I.C. e a construção da identidade}

A diferenciação grupal é organizada através dos estereótipos que apresentam dimensões cognitivas, avaliativas e afetivas que pressionam para a apropriação das representações tradicionais que circulam no seu grupo (Tajfel, 1974). Considerando que os indivíduos têm papel ativo neste processo, embora exista uma representação generalizada acerca do grupo étnico cigano, o contato intergrupal possibilita um campo de reelaboração dos significados que modulam as relações entre os grupos sociais, sejam elas solidárias ou conflituosas. Assim, para as mulheres rurais entrevistadas, a própria representação do que é ser cigano, não é homogênea, visto que podem se apropriar de modo particular das representações difundidas, assimilando ou não as representações tradicionais.

No caso do presente estudo, os estereótipos compartilhados pelas mulheres rurais em relação ao ser cigano contêm uma série de características negativamente valorizadas: os ciganos são percebidos como sujos, amaldiçoados, pessoas que pedem, roubam, que buscam uma maneira fácil de ganhar dinheiro sem trabalhar, que enganam os outros e que viajam constantemente, não tendo uma moradia fixa; são tidos, portanto, como um povo com uma cultura estranha (Fandos \& Martinez, 1999).

No Quadro 1, sistematizamos a realidade empírica e os conceitos teóricos relevantes à análise dos processos identitários desencadeados no encontro entre os grupos rural e cigano, a partir de mulheres rurais não ciganas que vivem em contexto comunitário. 
QUADRO 1

Esquema empírico e teórico do estudo a partir da Teoria da Identidade Social

Quadro esquemático: caracterização empírica e teórica do estudo

\begin{tabular}{|c|c|c|c|c|}
\hline $\begin{array}{l}\text { Categorização } \\
\text { social }\end{array}$ & \multicolumn{3}{|c|}{ - Produção das categorias sociais no imaginário social } & $\begin{array}{l}\text { Categorias sociais: grupos ciganos - gru- } \\
\text { pos rurais. } \\
\text { Generalização de estereótipos e formação } \\
\text { de categorias. } \\
\text { Imaginário ocidental: ciganos como sujos, } \\
\text { ladrões e amaldiçoados. }\end{array}$ \\
\hline $\begin{array}{l}\text { Comparação } \\
\text { social }\end{array}$ & \multicolumn{3}{|c|}{$\begin{array}{l}\text { - Relação entre os grupos sociais em determinado con- } \\
\text { texto } \\
\text { - Estado de conflito entre os grupos em comparação } \\
\text { social }\end{array}$} & $\begin{array}{l}\text { Passagem de categorias sociais a grupos de } \\
\text { pertencimento: Nós somos da comunidade } \\
\text { rural e eles são ciganos, os de fora. }\end{array}$ \\
\hline \multirow{6}{*}{$\begin{array}{l}\text { Identidade } \\
\text { social }\end{array}$} & \multirow{6}{*}{ 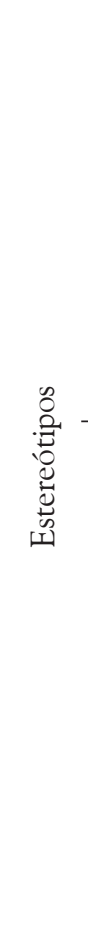 } & \multirow{3}{*}{ 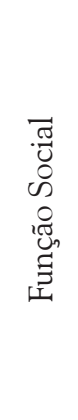 } & $\begin{array}{l}\text { Função justificadora } \rightarrow \text { Produção de ideo- } \\
\text { logias que justifiquem o status do grupo. }\end{array}$ & \multirow{3}{*}{$\begin{array}{l}\text { Entre os estereótipos que as mulheres ru- } \\
\text { rais entrevistadas apresentam acerca dos } \\
\text { ciganos estão: sujos, ladrões, criminosos, } \\
\text { andarilhos, pedintes e praguejantes. } \\
\text { O processo de simplificação ocorre através } \\
\text { da associação dos estereótipos que circu- } \\
\text { lam no imaginário social, a partir do "ci- } \\
\text { gano generalizado", para conseguir lidar } \\
\text { com os ciganos que estão em contato com } \\
\text { a comunidade rural. }\end{array}$} \\
\hline & & & $\begin{array}{l}\text { Explicação causal } \rightarrow \text { Processo de simplifi- } \\
\text { cação do complexo sistema de categoriza- } \\
\text { ção do outro. }\end{array}$ & \\
\hline & & & $\begin{array}{l}\text { Diferenciação social } \rightarrow \text { Manutenção da dis- } \\
\text { tintividade positiva em relação ao in-group. }\end{array}$ & \\
\hline & & \multirow{3}{*}{ 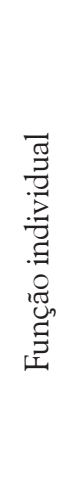 } & $\begin{array}{l}\text { Dimensão cognitiva } \rightarrow \text { O indivíduo reco- } \\
\text { nhece seu pertencimento a determinado } \\
\text { grupo social e o não pertencimento ao gru- } \\
\text { po de oposição. }\end{array}$ & \multirow{3}{*}{$\begin{array}{l}\text { O medo surge das práticas que não podem } \\
\text { ser estereotipadas, as quais estão direta- } \\
\text { - mente relacionadas à dimensão mística. } \\
\text { conflito místico é um dos importantes pro- } \\
\text { cessos que produzem campos identitários } \\
\text { na relação entre os ciganos e a comunida- } \\
\text { - de rural, sustentando práticas de exclusão } \\
\text { pelas entrevistadas e a consequente defesa } \\
\text { do seu espaço endogrupal. }\end{array}$} \\
\hline & & & $\begin{array}{l}\text { Dimensão avaliativa } \rightarrow \text { Atribuição de ele- } \\
\text { mentos positivos ao próprio grupo e negati- } \\
\text { vos ao out-group. }\end{array}$ & \\
\hline & & & $\begin{array}{l}\text { Dimensão afetiva } \rightarrow \text { Orientação afetiva } \\
\text { dos processos de identificação segundo a } \\
\text { dimensão avaliativa - sentimentos positivos } \\
\text { para o in-group e negativos ao out-group. }\end{array}$ & \\
\hline
\end{tabular}

Como podemos observar no Quadro 1, os estereótipos possuem importantes funções para o grupo social (atribuição de causalidade social, justificação social e diferenciação social) (Hogg $\&$ Abrams, 1988), processos que atuam na rede de produção e circulação do conteúdo simbólico, fornecendo recursos para que o grupo se proteja e, consequentemente, assegure aos seus membros uma auto-imagem positiva (Tajfel, 1982c, 1983). A dinâmica intergrupal, fundada na comparação social -orientada por crenças e valores grupais -, põe em evidência práticas que se relacionam a valores muito importantes para as mulheres rurais, como o trabalho, a higiene, a religião e a propriedade privada. A categoria trabalho é um dos pontos fortes nesse conflito. As mulheres rurais concebem que a sobrevivência honesta só é possível através do trabalho, pois é por meio dele que se sustenta a família. Dessa forma, o ato de roubar, ou mesmo de pedir, torna-se ofensivos aos valores associados ao modo de vida rural, que implica o esforço familiar para a sobrevivência. 
Entender o contexto social de inserção dos grupos é importante para a compreensão de como certas representações são transmitidas e justificadas (Souza, 1995). Algumas ocorrências, por mais imprevisíveis que sejam, podem contribuir para reforçar os estereótipos e adquirir importância prática nas relações intergrupais. A crença de que se deve ter cautela ao lidar com os ciganos, foi reforçada por um evento que marcou os moradores. Todas as entrevistadas se referiram a um tiroteio que ocorreu na comunidade durante um casamento cigano, em virtude de um conflito interno ao grupo. A ocorrência foi incorporada à memória social da comunidade e a partir dela as entrevistadas justificam como se deve ter cuidado ao lidar com o grupo cigano.

Um dos elementos que compõem o estereótipo é o poder místico atribuído às mulheres ciganas. Mesmo sabendo que esse poder pode ser percebido como ilusório pelas mulheres rurais, as ciganas dele fazem uso para amedrontar e, assim, conseguir o que desejam. Essa realidade acaba por determinar práticas de exclusão encobertas por práticas solidárias, como é o caso de algumas mulheres rurais que preferem atender rapidamente aos pedidos das ciganas, visto que se não o fizerem podem ser "amaldiçoadas". O ato de atender aos pedidos é justificado mais pelo interesse em mantê-las afastadas do que por solidariedade e, neste contexto, o medo apresenta-se como marcador identitário.

Algumas marcas distintivas dos grupos rural e cigano, respectivamente, puderam ser observadas: a fixação territorial vs. o nomadismo, o trabalho como valor vs. o trabalho como contra-valor, um grupo agrícola que vive do que produz na terra vs. um grupo que vive de trocas e barganhas, e a mística das rezas cristãs vs. um grupo reconhecido por possuir práticas místicas como a de ler a sorte, do poder da benzedura e de "jogar praga". Essas especificidades grupais podem agravar os conflitos enfrentados pelos ciganos em suas relações com os não-ciganos uma vez que tanto a comunidade rural quanto a cigana possui mecanismos de proteção, alicerçados na identidade étnica pelos ciganos e na identidade campesina, no que se refere à organização social, religiosa e agrária pelo grupo rural.
Os dados referentes ao endogrupo rural revelaram um arranjo social a partir da organização comunitária. A vida dos que vivem neste espaço prevê a participação nas atividades religiosas, nos grupos folclóricos, nos trabalhos destinados ao manejo agropecuário, segundo critérios relacionados a gênero e idade. Ser mulher nesta comunidade implica, portanto, o domínio da casa, das pequenas criações e horta, e, prioritariamente, do cuidado com os filhos.

As representações endogrupais revelaram a identificação das participantes como batalhadoras, honestas, humildes, mães e solidárias, enquanto em relação às ciganas as mulheres rurais destacaram o estranhamento quanto à aparência, o nomadismo, o medo que elas despertam nas pessoas e a prática de rogar pragas.

A casa rural é protegida dos ciganos, pois embora eles consigam entrar no território geográfico da comunidade, nas casas rurais os ciganos não entram. Nesta porta fechada pelas mulheres rurais abre-se uma importante discussão acerca das particularidades que organizam o campo identitário vinculado ao grupo rural. A análise através das identidades sociais nos permite uma compreensão mais clara desse conflito que se processa não apenas no nível de um encontro objetivo no mesmo território geográfico, mas primordialmente entre os modos de vida partilhados pela comunidade a partir de seus sistemas de crenças, valores e normas de comportamentos endo e exogrupais, os quais configuram os elementos centrais da rede identitária do grupo. Em outras palavras, não é o território geográfico e sim o território identitário simbólico que configura o campo conflituoso entre os grupos rural e cigano, embora, neste caso, o primeiro facilite ou disponibilize o arranjo do contexto para o segundo.

\section{Considerações finais}

Tomando como campo de investigação as significações acerca da cultura cigana, destacamos o cenário conflituoso no qual pudemos verificar as estratégias de proteção grupal e o empenho em demarcar um território identitário nas narrativas de 
membros de uma comunidade rural. Como Velho (2003) esclarece, na dinâmica grupal persiste o esforço para a "manutenção das fronteiras sociais e de um modelo em que o in-group está permanentemente ameaçado pelo stranger e pelo outsider" (p. 113) e esse movimento tem uma participação basilar na construção das identidades sociais.

A análise das narrativas colhidas no grupo nos permitiu identificar o sentimento de medo como importante orientador das práticas relacionadas ao grupo cigano. Esse resultado confirma características presentes no imaginário social amplamente difundido acerca dos ciganos, seja no território brasileiro seja nos outros países onde vivem. São concebidos geralmente como um grupo de ladrões, malfeitores e amaldiçoados, capazes de fazer mal aos grupos com os quais se relacionam (Silva \& Silva, 2000).

A diferenciação endogrupal positiva enfatizada pelas mulheres rurais em confronto com as ciganas processa-se especialmente na dimensão mística característica dos dois grupos, acrescida das estratégias de proteção utilizadas pelo endogrupo rural em relação à presença estrangeira na comunidade. A ênfase na prática de rogar praga associada ao poder da maldição atribuído aos ciganos se confronta com as crenças que estruturam a própria comunidade rural em seu universo religioso, e a prática de pedir nas casas se configura como contra-valor para o grupo rural, ferindo outra dimensão estruturante do seu modo de vida, o trabalho. $\mathrm{O}$ medo dos ciganos revela que eles são representados como uma ameaça para o grupo rural, não apenas pelo confronto entre formas de vida diferentes, mas pelo poder que é atribuído ao grupo.

Os resultados encontrados indicam a importância de se procurar compreender a dinâmica existente entre representações e identidades sociais, como já indicaram Breakwell (1993) e Souza (1995), entre outros. Com base nas contribuições da Teoria da Identidade Social (Tajfel, 1983), podemos entender como os indivíduos se posicionam em relação à sua rede de pertenças grupais, construindo suas identidades, múltiplas e processuais, sempre motivados pela busca de uma autoimagem positiva. Constatamos que uma das principais funções dos grupos sociais consiste em proteger o autoconceito de seus membros a partir da atribuição de valores positivos ao próprio grupo e, conseqüentemente, de valores negativos aos outros grupos, identificados como opositores na inevitável comparação social estabelecida, conforme já enfatizaram Hogg e Abrams (1988) e Tajfel (1982c, 1983).

Se, como preconiza a Teoria da Identidade Social, tendemos a elaborar identidades sociais positivas, uma importante questão a ser considerada é como agem os grupos definidos através de atributos negativos. Esta parece ser a situação dos negros em um mundo racista, das mulheres em um mundo machista, dos homossexuais em um mundo heterossexista ou mesmo dos ciganos como um dos grupos depositários do medo no mundo ocidental. A discussão acerca do medo provocado por um "outro" que compõe as minorias sociais parece revelar não apenas os elementos e estratégias utilizadas pelos grupos envolvidos, mas principalmente os valores e interesses ideológicos em jogo na sociedade. Conhecer esses "outros", sua organização, suas práticas e costumes, através dos recursos analíticos disponíveis no campo acadêmico, poderia contribuir para a reflexão sobre determinadas práticas que acabam por desqualificar diretamente o outro e a sua forma de viver, concretizando a exclusão social.

\section{Referências}

Alexandre, J. D. (2003). Ciganos, Senhores e Galhardós: Um estudo sobre percepções e avaliações intra e intergrupais na infância. Dissertação de Mestrado em Psicologia Social e Organizacional, Instituto Superior de Ciências do Trabalho e da Empresa, Portugal.

Amerio, P. (2004). Présentation : dimensions psychosociales du sentiment d'insécurité. Psychologie et Société, 7, 7-10.

Bonomo, M., Trindade, Z. A., Souza, L. \& Coutinho, S. M. S. (2008). Representações sociais e identidade em grupos de mulheres ciganas e rurais. Revista Portuguesa de Psicologia, 22, 151-178.

Breakwell, G. M. (1993). Integrating paradigms, methodological implications. Em G. M. Breakwell 
\& D. V. Canter (Orgs.), Empirical approaches to social representations (pp. 180-201). Oxford: Clarendon Press.

Camargo, B. V. (2005). Alceste: um programa informático de análise quantitativa de dados textuais. Em A. S. P. Moreira (Ed.), Perspectivas teórico-metodológicas em representações sociais (pp. 511-540). João Pessoa: UFPB.

Carvalho, A. M., Machado, M. G. M. \& Suyama, E. (2002). Afetividade, Cultura e Cuidado: Possibilidades para o Desenvolvimento da Criança. Em S. A. S. Leite (Org.), Cultura, Cognição e Afetividade: A Sociedade em Movimento (pp. 39-67). São Paulo: Casa do Psicólogo.

Coutinho, E. A. S. M. (2002). Ciganos: as vítimas esquecidas do holocausto. Amnistia Informação Internacional, 10, 4-5.

Delumeau, J. (2007). Medos de ontem e de hoje. Em A. Novaes (Org.), Ensaios Sobre o Medo (pp. 39-52). São Paulo: Editora Senac-Sesc.

Fandos, M. \& Martinez, M. J. (1999). Estereótipos em el cómic. Comunicar, 12, 117-119.

Fiamme nel campo rom raid nelle baracche disabitate. (2008, 14 luglio). La Repubblica.it, 3. Disponível em http://ricerca.repubblica.it/repubblica/ archivio/repubblica/2008/07/14/fiamme-nel-camporom-raid-nelle-aracche.html

Fiorin, J. L. (2004). Linguagem e ideologia. São Paulo: Atica.

Fonseca, I. (1996). Enterrem-me em pé - a longa viagem dos ciganos. São Paulo: Companhia das Letras.

Funari, P. P. A. (2006). Guerra do Peloponeso. Em M. Demétrio (Org.), História das Guerras (pp. 18-45). São Paulo: Contexto.

Fundación Secretariado Gitano. (2005). Dossier № 7. Madrid: Autor.

Glassner, B. (2003). A cultura do medo. São Paulo: Francis.

Hogg, D. \& Abrams, M. A. (1988). Social identifications: A social psychology of intergroup relations and group processes. London: Routledge.

Hogg, M. A., Abrams, D., Otten, S. \& Hinkle, S. (2004). The social identity perspective: Intergroup relations, self-conception, and small groups. Small Group Research, 35 (3), 246-276.
Kronberger, N. \& Wagner, W. (2002). Palavras-chave em contexto: análise estatística de textos. Em M. W. Bauer \& G. Gaskell (Orgs.) e P. A. Guareschi (Trad.), Pesquisa qualitativa com texto, imagem e som (pp. 416-441). Petrópolis: Editora Vozes.

Leite, I. (1999). Emoções, sentimentos e afetos: uma reflexão sócio histórica. Araraquara: J. M. Editora.

Lima, L. C. (2008). Programa Alceste, primeira lição: a perspectiva pragmatista e o método estatístico. Revista de Educação Pública, Cuiabá, 33, 83-97.

Magano, O. (2007). A (re)produção das desigualdades sociais dos ciganos em Portugal. Disponivel em http:// conferencias.iscte.pt/index.php?cf $=3$

Martins, J. M. (2004). A lógica das emoções: na ciência e na vida. Petrópolis: Vozes.

Moraes, D. (2002). Imaginário social e hegemonia cultural. Disponivel em http://www.acessa.com/gramsci/? page $=$ visualizar\&id $=297$

Moser, G. (2004). Les conditions psychosociales et environnementales d'un sentiment de sécurité. Psychologie et Société, 7, 11-24.

Reinert, M. (1990). Alceste, une méthodologie d'analyse des données textuelles et une application : Aurélia de Gérard de Nerval. Bulletin de Méthodologie Sociologique, 26, 24-54.

Sawaia, B. B. (2001). Identidade - uma ideologia separatista? Em B. Sawaia (Org.), As artimanhas da exclusão-Análise psicossocial ética da desigualdade social (pp. 119-127). Petrópolis: Vozes.

Silva, M. C. \& Silva, S. (2000). Práticas e representações sociais face aos ciganos - O caso de Oleiros, Vila Verde. Em Anais do IV Congresso Português de Sociologia (pp. 1-18). Coimbra: Associação Portuguesa de Sociologia.

Souza, L. (1995). "Olho por olho, dente por dente": representação de justiça e identidade social. Tese de Doutorado em Psicologia, Instituto de Psicologia da Universidade de São Paulo, São Paulo, Brasil.

Souza, L. (2004). Processos de categorização e identidade: solidariedade, exclusão e violência. Em L. Souza \& Z. A. Trindade (Orgs.), Violência e exclusão: convivendo com paradoxos (pp. 57-74). São Paulo: Casa do Psicólogo.

Tajfel, H. (1970). Experiments in intergroup discrimination. Scientific American, 223, 96-102. 
Tajfel, H. (1972). La catégorisation sociale [Social categorization]. Em S. Moscovici (Ed.), Introduction à la Psychologie Sociale (pp. 272-302). Paris: Larousse.

Tajfel, H. (1974). Social identity and intergroup behavior. Social Science Information, 13, 65-93.

Tajfel, H. (1982a). Comportamento intergrupo e Psicologia Social da mudança. Em A. F. Barroso, B. M. Silva, J. Vala, B. M. Monteiro \& M. H. Castro (Orgs.), Mudança Social e Psicologia Social (pp. 13. 24). Lisboa: Livros Horizonte.

Tajfel, H. (1982b). Social psychology of inter-group relations. Annual Review of Psychology, 33, 1-39.

Tajfel, H. (1982c). Grupos humanos e categorias sociais I. Lisboa: Livros Horizonte.
Tajfel, H. (1983). Grupos humanos e categorias sociais II. Lisboa: Livros Horizonte.

Tajfel, H. (1984). The social dimension: European developments in social psychology. Cambridge, England: Cambridge University Press.

Vaz, A. D. (2005). José, Tereza, Zélia... E sua comunidade um território cigano. Revista Trilhos, 3 (3), 95-109.

Velho, G. (2003). Projeto metamorfose: antropologia das sociedades complexas. Rio de Janeiro: Jorge Zahar.

Wacquant, L. J. D. (2004). Que é gueto? Construindo um conceito sociológico. Revista de Sociologia e Política, 23, 155-164.

Walton, S. (2007). Uma historia das emoções. Rio de Janeiro: Record. 